https://helda.helsinki.fi

\title{
The sorption and diffusion of 133Ba in crushed and intact granitic rocks from the Olkiluoto and Grimsel in-situ test sites
}

\section{Muuri, Eveliina}

2018-02

Muuri , E , Matara-aho , M , Puhakka, E, Ikonen , J , Martin , A , Koskinen, L \&

Siitari-Kauppi , M 2018, ' The sorption and diffusion of 133Ba in crushed and intact granitic rocks from the Olkiluoto and Grimsel in-situ test sites ' , Applied Geochemistry , vol. 89 , pp.

138-149 . https://doi.org/10.1016/j.apgeochem.2017.12.004

http://hdl.handle.net/10138/298678

https://doi.org/10.1016/j.apgeochem.2017.12.004

acceptedVersion

Downloaded from Helda, University of Helsinki institutional repository.

This is an electronic reprint of the original article.

This reprint may differ from the original in pagination and typographic detail.

Please cite the original version. 


\section{Accepted Manuscript}

The sorption and diffusion of ${ }^{133} \mathrm{Ba}$ in crushed and intact granitic rocks from the Olkiluoto and Grimsel in-situ test sites

Eveliina Muuri, Minja Matara-aho, Eini Puhakka, Jussi Ikonen, Andrew Martin, Lasse Koskinen, Marja Siitari-Kauppi

PII: S0883-2927(17)30368-2

DOI: 10.1016/j.apgeochem.2017.12.004

Reference: $\quad$ AG 3999

To appear in: Applied Geochemistry

Received Date: 1 April 2017

Revised Date: 4 December 2017

Accepted Date: 4 December 2017

Please cite this article as: Muuri, E., Matara-aho, M., Puhakka, E., Ikonen, J., Martin, A., Koskinen, L., Siitari-Kauppi, M., The sorption and diffusion of ${ }^{133} \mathrm{Ba}$ in crushed and intact granitic rocks from the Olkiluoto and Grimsel in-situ test sites, Applied Geochemistry (2018), doi: 10.1016/ j.apgeochem.2017.12.004.

This is a PDF file of an unedited manuscript that has been accepted for publication. As a service to our customers we are providing this early version of the manuscript. The manuscript will undergo copyediting, typesetting, and review of the resulting proof before it is published in its final form. Please note that during the production process errors may be discovered which could affect the content, and all legal disclaimers that apply to the journal pertain. 
1 The sorption and diffusion of ${ }^{133} \mathrm{Ba}$ in crushed and intact granitic rocks from the Olkiluoto and Grimsel in-situ test sites

3 Eveliina Muuri ${ }^{\mathrm{a}}$, Minja Matara-aho ${ }^{\mathrm{a}}$, Eini Puhakka ${ }^{\mathrm{a}}$, Jussi Ikonen ${ }^{\mathrm{a}}$, Andrew Martin ${ }^{\mathrm{b}}$, Lasse

4 Koskinen $^{\mathrm{c}}$ and Marja Siitari-Kauppi ${ }^{\mathrm{a}}$

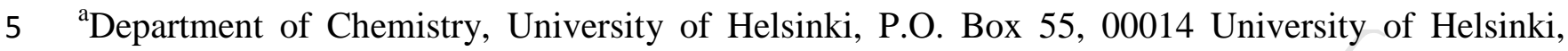

6 Finland

${ }^{b}$ Nagra (National Cooperative for the Disposal of Radioactive Waste), Wettingen, Switzerland

${ }^{\mathrm{c}}$ Posiva Oy, Finland

9 Corresponding author and contact e-mail: Eveliina Muuri, eveliina.muuri@helsinki.fi

KEYWORDS: sorption, diffusion, nuclear waste, crystalline rock, barium

HIGHLIGHTS: Specific surface area and competing ions had a clear effect on the sorption. Sorption on biotite was found to behave according to a three site ion exchange model. The concentration decrease of barium in the solution was largest in granodiorite.

\section{ABSTRACT}

The distribution coefficients of barium on Olkiluoto pegmatitic granite and veined gneiss, Grimsel granodiorite and their main minerals (quartz, plagioclase, potassium feldspar and biotite) were obtained by batch sorption experiments carried out as a function of the concentration of barium. The distribution coefficients on biotite and veined gneiss were modelled with the PHREEQC computing program. In addition, the diffusion of barium into rock cubes was also studied both experimentally and computationally and the rock cubes from the diffusion experiments were studied with autoradiography and scanning electron microscopy. The results showed that the distribution coefficients of barium were largest on biotite and the sorption as a function of barium concentration on all the minerals followed a similar trend. The distribution coefficients of barium on veined gneiss, pegmatitic granite and granodiorite followed the distribution coefficient trend of their main minerals and the distribution coefficients were largest on granodiorite due to the low salinity of the groundwater simulant. The distribution coefficients of barium on veined gneiss were of the same magnitude as on granodiorite because of the high biotite content of veined gneiss and those on pegmatitic granite were a magnitude smaller. It was also discovered that the distribution coefficients in saline water were considerably smaller than the results obtained in low salinity water, which suggests that competing ions play a significant role in the sorption of barium. Finally, the 
concentration decrease of barium in the solution in the diffusion experiments was largest in granodiorite which can be explained with both the porous structure of all the minerals of granodiorite leading to high accessible surface area and with the sorption properties of barium. It was discovered with autoradiography that the barium was mainly sorbed on the dark minerals of the rocks, but, additionally, barium sorption on plagioclase was also concluded to be significant. In addition, the sorbed barium could be seen with scanning electron microscopy on the biotite and calcite veins in the fissures of the rock in granodiorite and veined gneiss.

\section{INTRODUCTION}

Spent nuclear fuel in Finland will be disposed of in the crystalline granitic bedrock $400 \mathrm{~m}$ below surface at the Olkiluoto site in a repository system that is based on a multiple barrier system consisting of copper-iron canisters isolated by bentonite and the bedrock (Miller and Marcos, 2007). The bedrock in the Olkiluoto site is considered suitable for the facility due to its stable tectonic setting, good quality, existing reducing conditions and low groundwater flow at the repository system depth (Posiva, 2012). However, the processes affecting the migration of the radionuclides from the nuclear fuel need to be taken into account when assessing the overall safety of the repository. It is therefore very important to study the sorption and diffusion properties of different radionuclides through laboratory and in-situ field work in order to assess the physical and chemical processes affecting the migration of radionuclides in the different release barriers of the repository including the bedrock.

The radionuclides occurring in the spent nuclear fuel have been divided into five priority classes in the Finnish safety calculations according to their relevance for the safety assessment; top priority, high priority (I), high priority (II), high priority (III) and low priority (Posiva, 2013). The first class is the top priority class containing the non-sorbing radionuclides which are expected to dominate the radioactive dose $\left({ }^{14} \mathrm{C},{ }^{36} \mathrm{Cl},{ }^{129} \mathrm{I}\right) .{ }^{226} \mathrm{Ra}$ is commonly placed in the low priority class but it needs to be taken into account in some calculation cases in the biosphere assessment as it is enriched in the system as the daughter nuclide in the uranium series (Haavisto, 2014; Posiva, 2009). In contrast with the Finnish safety calculations, it has been noted in some scenarios in the Swedish safety calculations that one of the largest long-term radiological risks to humans over a certain time span will be caused by radium (Svensk Kärnbränslehantering AB, 2006). Radium occurs in the oxidation state + II and its compounds are relatively soluble which makes radium mobile should a leakage occur in the repository (Lehto and Hou, 2011). In addition, the activity of radium in the spent nuclear fuel will increase reaching its maximum after approximately 300,000 years (Hedström, 2013). However, the investigation of ${ }^{226} \mathrm{Ra}$ is complicated because it is an alpha emitter in the 
uranium series and chemical separation is needed for the alpha spectrometry. In addition, the strongest gamma transition of ${ }^{226} \mathrm{Ra}$ is the same and has similar intensity as that of a peak of ${ }^{235} \mathrm{U}$ (Lehto and Hou, 2011). It is therefore common to use the gamma emitting ${ }^{133} \mathrm{Ba}$ as an analogue for

${ }^{226} \mathrm{Ra}$. Barium and radium are both alkali earth metals with very similar chemical properties and, as a consequence, ${ }^{133} \mathrm{Ba}$ is one of the nuclides studied in the in-situ experiments (Widestrand et al., 2004; Voutilainen et al., 2014).

The sorption and diffusion of barium have been studied in laboratory and in-situ conditions (Möri et al., 2003; Hakanen et al., 2014). However, long-term in-situ experiments are time-consuming and costly due to which only few of them have been carried out. In 2009 a long-term diffusion project was started in the Grimsel Test Site in Switzerland to evaluate the diffusion and sorption properties of radionuclides in the in-situ conditions (Jokelainen et al., 2013; Soler et al., 2015; Ikonen et al., 2016a; Ikonen et al, 2016b). In addition, several in-situ diffusion tests are currently ongoing in the Olkiluoto site in Finland (Voutilainen et al., 2014). All these experiments need supporting laboratory studies as it is highly important to compare the scarce in-situ results with the laboratory experiments to better assess their relevancy.

In this study, the sorption and diffusion of barium were investigated with laboratory experiments and with computer modelling to support the results from the in-situ experiments. The laboratory experiments were conducted in conditions that were resembling the conditions in the Grimsel and Olkiluoto in-situ test sites. The sorption of barium was studied with batch sorption experiments in a broad concentration range $\left(10^{-9}-10^{-3} \mathrm{M}\right)$ in Grimsel granodiorite, Olkiluoto pegmatitic granite and veined gneiss, and their main minerals; quartz, plagioclase, potassium feldspar and biotite. The diffusion of barium was studied in rock cubes of granodiorite, pegmatitic granite and veined gneiss as a function of time. Groundwater simulants resembling the fracture waters in the Grimsel and Olkiluoto sites were used in the batch sorption experiments and in the diffusion experiments. The sorption results were modelled with the PHREEQC computer program after justifying the sorption model with molecular modelling based on density functional theory (DFT). The COMSOL Multiphysics software was employed in the modelling of the diffusion results. The aim of the diffusion modelling was to better describe the retention of barium in intact crystalline rock in the conditions of the geological repository.

2. MATERIALS AND METHODS

2.1. The geology and mineralogy of the Grimsel and Olkiluoto site 
The Grimsel Test Site is located in central Switzerland at an altitude of 1,730 metres in the granitic rock of the Aare Massif which is consisted of a metasedimentary envelope that was intruded by Hercynian granitoids (320-280 Ma) (Tachi et al., 2015). All the rocks in the area have been affected by the Alpine greenschist metamorphism and deformation and the still ongoing post-metamorphic regional uplift (Möri et al., 2003a). The bedrock in the Grimsel test site area is composed of granodiorite (Hoehn et. al, 1998) and Aare granite and the long-term diffusion tests have been conducted in the areas consisted of granodiorite (Hu and Möri, 2008; Möri et al., 2003b). Grimsel granodiorite is homogeneous, medium grained and slightly preferentially-oriented with brittle structural features of cataclastic fault breccias and discrete faults (Möri et al., 2003b). The main minerals of granodiorite are quartz, plagioclase, potassium feldspar and biotite (Table 1). Other minerals, which do not exceed $5 \%$ in volume, are green amphibole (hornblende), muscovite, epidote, titanite and opaque minerals (Jokelainen et al., 2013).

Table 1. The average mineral compositions of veined gneiss, pegmatitic granite and granodiorite in volume percentage by point counting method (500 points/thin section), where + is optically observed. (Ikonen et al., 2015, Jokelainen et al., 2013).

\begin{tabular}{llll}
\hline Mineral & Veined gneiss & Pegmatitic granite & Granodiorite \\
\hline Quartz & 30.2 & 36.0 & 32.8 \\
Plagioclase & 19.0 & 44.8 & 36.5 \\
Potassium feldspar & 4.4 & 12.8 & 34.4 \\
Biotite & 35.2 & + & 6.4 \\
Muscovite & 2.2 & 5.0 & 2.1 \\
Chlorite & - & + & 0.3 \\
Cordierite & 2.2 & - & - \\
Garnet & - & 1.4 & - \\
Sillimanite & 6.6 & - & - \\
Epidote & + & + & 1.1
\end{tabular}


Apatite

Opaque

0.2

Titanite

Amphibole
$+$
0.3

3.2
111

The Olkiluoto site, on the other hand, is an island located on the coast of south-western Finland where the repository system will be built in the depth of 400 metres below the surface. The site is situated in the part of the Fennoscandian shield where the postglacial land uplift is moderate, about $6 \mathrm{~mm}$ annually. The latest glaciation in southern Finland lasted over 50,000 years and the ice sheet retreated from the Olkiluoto site about 10,000 years ago (Pitkänen et al., 1996). The bedrock in the area is of heterogeneous Archaean crystalline rock. The degree of heterogeneity and foliation change rapidly in the bedrock in Olkiluoto area where the main rock type in the depth of the deposition facility is veined gneiss (43\%) with shorter sections of pegmatitic granite (20\%) (Aaltonen et al., 2016). Pegmatitic granite can be found in the host rock as coarse-grained irregular masses whereas veined gneiss shows a high level of deformation with powerful foliation. The main minerals of veined gneiss are quartz, plagioclase, biotite and potassium feldspar and the main minerals of pegmatitic granite are quartz, plagioclase and potassium feldspar (Table 1). (Posiva Oy, 2009; Kärki and Paulamäki, 2006; Ikonen et al, 2015)

\subsection{Groundwater simulants}

The groundwater in the Grimsel Test Site is alkaline and weakly saline with low ionic strength and few competing ions for barium (Mäder et al., 2006). The chemical composition of the groundwater simulant used in the experiments (Table 3) was prepared based on the fracture water data from the Grimsel Test Site (Mäder et al., 2006). The concentration of natural stable barium in the Grimsel groundwater has been analysed by inductively coupled plasma mass spectrometry (ICP-MS) in Paul Scherrer Institute (PSI) in Switzerland and it has been found to be approximately $9.2 \cdot 10^{-9} \mathrm{M}$.

Table 3. The chemical composition of the Grimsel and Olkiluoto groundwater simulants used in the experiments. (Mäder et al., 2006; Voutilainen et al., 2014)

\begin{tabular}{lll}
\hline Component & \multicolumn{2}{c}{ Molality } \\
\hline & Grimsel & Olkiluoto \\
$\mathrm{pH}$ & 9.7 & 6.9
\end{tabular}




\begin{tabular}{lll}
$\mathrm{Na}^{+}$ & $6.9 \cdot 10^{-4}$ & $1.2 \cdot 10^{-1}$ \\
$\mathrm{~K}^{+}$ & $5.0 \cdot 10^{-6}$ & $2.0 \cdot 10^{-4}$ \\
$\mathrm{Ca}^{2+}$ & $1.4 \cdot 10^{-4}$ & $1.3 \cdot 10^{-2}$ \\
$\mathrm{Mg}^{2+}$ & $6.2 \cdot 10^{-7}$ & $1.4 \cdot 10^{-3}$ \\
$\mathrm{HCO}_{3}^{-}$ & $4.5 \cdot 10^{-4}$ & $2.0 \cdot 10^{-4}$ \\
$\mathrm{Cl}^{-}$ & $1.6 \cdot 10^{-4}$ & $1.4 \cdot 10^{-1}$ \\
$\mathrm{SO}_{4}{ }^{2-}$ & $6.1 \cdot 10^{-5}$ & $3.1 \cdot 10^{-6}$ \\
$\mathrm{Br}^{-}$ & $3.8 \cdot 10^{-7}$ & $4.1 \cdot 10^{-4}$ \\
$\mathrm{~F}^{-}$ & $3.6 \cdot 10^{-4}$ & $7.9 \cdot 10^{-5}$ \\
\hline
\end{tabular}

The fracture groundwater in the Olkiluoto site, on the other hand, is mainly of $\mathrm{Na}-\mathrm{Cl}$ type with the $\mathrm{pH}$ values ranging from 7.3-8.0. In addition, the groundwater is brackish at the depths from $40 \mathrm{~m}$ to $500 \mathrm{~m}$ although some fracture waters from the area have been noticed to have a maximum chloride content of up to tens of grams per litre. It has been determined that the concentration of natural stable barium ranges from $5.9 \cdot 10^{-7} \mathrm{M}$ to $1.9 \cdot 10^{-5} \mathrm{M}$ in the Olkiluoto site (Hellä et al., 2014). The groundwater contains seawater that resembles the present water in the Baltic Sea. The chemical composition of the Olkiluoto groundwater simulant used in the experiments (Table 3) was prepared based on the fracture water data from boreholes KR-14 and KR-13 close to the Repro site (Voutilainen et al., 2014).

Biotite is found commonly in crystalline rocks and it is also one of the main components of the rock samples used in this study. Its end member in solid solution series is phlogopite, $\mathrm{KMg}_{3} \mathrm{AlSi}_{3} \mathrm{O}_{10}(\mathrm{OH})_{2}$, where all the iron ions of biotite have been substituted by magnesium. In this study molecular modelling methods based on density functional theory (DFT) were used to investigate the crystalline and surface structures of phlogopite and sorption onto phlogopite surfaces. The possible sorption of ions was studied on the hydroxylated (110) surface of phlogopite, which is its typical edge surface. The first objective was to find out how the surface structure changes when potassium ions on the surface are replaced with barium. However, the ion exchange reaction mechanism was not studied. The second objective was to check if barium cations are sorbed on the same sites as cesium cations.

155 The calculations were performed with the CASTEP (CAmbridge Serial Total Energy Package by 156 Clark et al., 2005) code implemented into Materials Studio versions 8.0 (Dassault Systemès, 2014). 
The modelling is based on solving the total electronic energy and overall electronic density distribution in order to define the energetically stable structures for minerals and sorbing species (Leach, 2001). The exchange-correlation was described with generalized gradient approximation GGA-PBE. As a compromise between the accuracy and computational time of calculations, the ultrasoft pseudopotentials were used for each element. The used potentials were Al_00PBE.usp for aluminum, Ba_00PBE.usp for barium, Cs_00PBE.usp for cesium, H_00PBE.usp for hydrogen, K_00PBE.usp for potassium, Mg_00.usp for magnesium, O_soft00.usp for oxygen, and Si_soft00.usp for silicon. The kinetic cut-off energy for a plane wave expansion of the wave function was $310 \mathrm{eV}$.

\subsection{Batch sorption experiments}

The minerals chosen for the batch sorption experiments in this study were quartz, plagioclase, potassium feldspar and biotite. Additionally, granodiorite from the Grimsel Test Site and veined gneiss and pegmatitic granite from the Olkiluoto site were also studied. The samples for the batch sorption experiments were crushed by milling and sieved to the grain size of $<0.3 \mathrm{~mm}$. The purity and the mineral composition of the minerals and rocks was characterized with the X-ray diffraction (XRD) method in the Geological Survey of Finland and the specific surface areas of the minerals and rocks were determined at Chalmers University with Kr-BET using a gas adsorption analyzing instrument (Micromeritics ASAP2020).

Crushed minerals and rocks were first equilibrated with the groundwater simulants in liquid scintillation vials with a solid to solution ratio of $50 \mathrm{~g} / \mathrm{L}$ after which the vials were agitated for two weeks. The investigated concentrations of barium $\left(1 \cdot 10^{-3} \mathrm{M}, 1 \cdot 10^{-4} \mathrm{M}, 1 \cdot 10^{-5} \mathrm{M}, 1 \cdot 10^{-6} \mathrm{M}, 1 \cdot 10^{-7}\right.$ $\left.\mathrm{M}, 1 \cdot 10^{-8} \mathrm{M}, 1 \cdot 10^{-9} \mathrm{M}\right)$ were added to the samples with a nonradioactive barium salt $\left(\mathrm{BaCl}_{2}\right.$, SigmaAldrich) and a radiotracer of ${ }^{133} \mathrm{Ba}\left(\mathrm{BaCl}_{2}\right.$ in $0.1 \mathrm{M} \mathrm{HCl}$, Eckert \& Ziegler) after which the vials were again agitated for two weeks. The solutions were not buffered but they were let to equilibrate with the minerals and air and the $\mathrm{pH}$ of each solution was measured after the equilibration. The amount of the added radiotracer of barium was $620 \mathrm{~Bq} / 10 \mathrm{~mL}$ (carrier $1.30 \cdot 10^{-9} \mathrm{~g} / \mathrm{L}$ ). The samples were centrifuged (15 min, $4000 \mathrm{rpm}$ with Sigma 3-16 KL) after the equilibration and the supernatant was pipetted to liquid scintillation vials. The $356 \mathrm{keV}$ (intensity $62.1 \%$ ) peak of ${ }^{133} \mathrm{Ba}$ was measured from the supernatant with a Perkin Elmer automatic 1480 WIZARD 3" gamma counter with a 20 min counting period. The detection limit for ${ }^{133} \mathrm{Ba}$ was $0.37 \mathrm{~Bq}$. The distribution coefficients $K_{d}$ of barium on the investigated minerals and rock samples were calculated from the percentages of barium sorption acquired from the relative activities of the measurements. 
190

191

The diffusion experiments were conducted on $1 \mathrm{~cm} \times 1 \mathrm{~cm} \times 1 \mathrm{~cm}$ rock cubes that were sawed from the rock cores that have been cored from the Olkiluoto and Grimsel sites. The rock cubes were placed on the bottom of small vessels so that all other surfaces of the rock were in free contact with the tracer solution but the one facing the vessel. The cubes were equilibrated with the groundwater simulant $(15 \mathrm{~mL})$ for two weeks after which the radiotracer of ${ }^{133} \mathrm{Ba}(4600 \mathrm{~Bq} / 15 \mathrm{~mL})$ and stable barium as $\mathrm{BaCl}_{2}\left(1 \cdot 10^{-6} \mathrm{M}\right)$ was added. The concentration decrease of the tracer in the solution was monitored for six months by pipetting $10 \mathrm{~mL}$ of the solution and measuring the activity of ${ }^{133} \mathrm{Ba}$ with gamma spectrometry after which the solution was pipetted back into the vessel containing the rock cube and the solution. The monitoring was first done twice a day and later once a week when the tracer concentration decrease slowed down. After the termination of the diffusion experiments, the rock cubes were sawed to thin layers (approximately $1 \mathrm{~mm}$ in thickness), polished and studied with autoradiography and field emission scanning electron microscope (FE-SEM) at the Finnish Geosciences Research Laboratory (SGL).

\subsection{Digital autoradiography}

The surfaces of the rock cubes that had been in contact with the tracer solution in the diffusion experiments were placed into exposure cassettes on phosphor screens (Fuji Imaging Plate BASTR2025, Fuji Photo Film Co., Ltd., Tokyo, Japan) and exposed for one day. After this the imaging plates were scanned with a Fujifilm Life Sciences Imaging Systems FLA5100 with $10 \mu \mathrm{m}$ resolution. The data obtained from the scans was stored as digital files and analyzed with the image analysis program Aida (Raytest Isotopenmessgeräte GmbH, Straubenhardt, Germany).

\subsection{Scanning electron microscopy}

The rock surfaces that had been in contact with the tracer solution in the diffusion experiments were studied at the Finnish Geosciences Research Laboratory (SGL) with the Jeol JSM-7100F Schotky field emission scanning electron microscopy (FE-SEM) equipment having a high resolution option and equipped with an Oxford Instruments EDS system of a X-mas $80 \mathrm{~mm}^{2}$ silicon drift detector (SDD). The elemental composition of the samples was investigated in order to detect the retained barium on the mineral surfaces. The detection limit of Ba in the EDS system was $0.1 \mathrm{wt} \%$.

\subsection{Sorption modelling}

The sorption modelling was performed with PHREEQC for Windows (Parkhurst and Appelo, 1999), which is a geochemical modelling tool used to simulate a variety of geochemical processes, 
e.g. the sorption of trace metals on minerals. The model used in this study was modified from the original multi-site sorption model of Bradbury and Baeyens (2000) which provides good estimations of the distribution coefficients of cesium according to previous studies done in similar conditions (Kyllönen et al., 2014; Muuri et al., 2016). The sheet silicate structure of biotite is close to the clay mineral structures in argillaceous rocks, which were the rocks used in the study by Bradbury and Baeyens (2000). Molecular modelling was done to confirm that barium cations can be sorbed on the same sites as cesium cations on biotite and, as a consequence, a similar multi-site sorption model was used for barium as has been used for cesium. The sorption processes in PHREEQC are described as binary ion exchange reactions according to the Gaines-Thomas convention (Appelo and Postma, 2005), where the cation exchange reaction may be written with the cation exchange sites $\left(X^{-}\right)$as:

$N a-X+\frac{1}{2} B a^{2+} \leftrightarrow \frac{1}{2} B a-X_{2}+N a^{+}$

The distribution of species and the selectivity coefficient $K_{c}$ can thus be represented as: ${ }_{\mathrm{Na}}^{\mathrm{Ba}} K_{C}=\frac{\left[\mathrm{Ba}-\mathrm{X}_{2}\right]\left[\mathrm{Na}^{+}\right]}{[\mathrm{Na}-\mathrm{X}]\left[\mathrm{Ba}^{2+}\right]^{0.5}}$

The $K_{c}$ value is the affinity of each specific site type available for ion exchange and a higher $K_{c}$ value suggests a higher affinity for barium and thus stronger sorption. The $K_{c}$ values are treated in the model as $\log K_{c}$ and, as a result, all reference values are referred to as such.

\subsection{Diffusion modelling}

The diffusion of barium in the rock cubes was modelled with the COMSOL software (COMSOL, 2016) with Transport of Diluted Species in Porous Media node describing diffusion with the Fick's laws. In the model, diffusion was assumed as the only transport process and no advection or flow was taken into account using a simplified homogeneous model with effective transport properties.

Diffusion is described by Fick's laws:

$F=-D \frac{\partial c}{\partial x}$

where $F$ is the flux $\left(\mathrm{mol} \mathrm{m} \mathrm{m}^{-2} \mathrm{~s}^{-1}\right), D$ is the diffusion coefficient $\left(\mathrm{m}^{2} / \mathrm{s}\right)$, and $c$ is the concentration $\left(\mathrm{mol} / \mathrm{m}^{3}\right)$.

$\varepsilon \frac{\partial c}{\partial t}=D_{e f f} \frac{\partial^{2} c}{\partial x^{2}}-\rho \frac{\partial q}{\partial t}$ 
where $\rho$ is the bulk density of the porous medium and $q$ is the sorbed concentration in the porous medium. The term $\partial q / \partial t$, on the other hand, represents a sink term due to the sorption of the solute (Boving and Grathwohl, 2001). Furthermore, the effective diffusion coefficient can be defined as:

$D_{e f f}=\frac{D_{a q} \varepsilon_{e f f} \delta}{\tau_{f}}$

where $D_{a q}$ is the aqueous diffusion coefficient in pure water, $\varepsilon_{\text {eff }}$ is the effective porosity, $\delta$ is the constrictivity and $\tau_{\mathrm{f}}$ is the tortuosity factor. The aqueous diffusion coefficient of barium in pure water is $8.48 \cdot 10^{-10} \mathrm{~m}^{2} / \mathrm{s}$ at $25{ }^{\circ} \mathrm{C}$ (Augustithis, 1983).

\section{RESULTS AN DISCUSSION}

\subsection{Minerals}

The minerals studied in the batch sorption experiments were quartz, plagioclase, potassium feldspar and biotite in addition to the granodiorite from the Grimsel Test Site and veined gneiss and pegmatitic granite from the Olkiluoto site. It was discovered in the XRD experiments in the Geological Survey of Finland that the quartz used in the sorption experiments was $95 \%$ pure $\mathrm{SiO}_{2}$ with two minor unidentified phases. Additionally, the biotite sample was $80 \%$ phlogopite, $\mathrm{KMg}_{3} \mathrm{AlSi}_{3} \mathrm{O}_{10}(\mathrm{OH})_{2}$, and $20 \%$ chlorite, $\left(\mathrm{Mg}_{5} \mathrm{Al}\right)\left(\mathrm{AlSi}_{3}\right) \mathrm{O}_{10}(\mathrm{OH})_{8}$. The potassium feldspar sample was found to be of the most stable polymorph, maximum low microcline, with inclusions of albite $(10 \%)$. Additionally, the plagioclase was revealed to have numerous impurities, such as inclusions and mixed grains with the composition of plagioclase (90\%), pyroxene (5\%), quartz (3\%), biotite (1 $\%)$ and chlorite $(1 \%)$. The mineral compositions of the granodiorite, veined gneiss and pegmatitic granite used in the experiments were found to resemble the compositions presented in Table 1 according to Jokelainen et al. (2013) and Ikonen et al. (2015). The granodiorite was consisted of plagioclase $(40 \%)$, quartz (30\%), potassium feldspar $(20 \%)$ and biotite $(5 \%)$. The veined gneiss sample consisted of quartz (20\%), plagioclase (15\%), potassium feldspar (10\%) and biotite (35 $\%)$. The pegmatitic granite sample, on the other hand, consisted of quartz (15\%), plagioclase (30 $\%)$, potassium feldspar (40\%) and mica (5\%). As a result of the studied rocks, the veined gneiss was richest in biotite whereas the pegmatitic granite was richest in potassium feldspar in the XRD analyses. However, the potassium feldspar content determined by the point counting method was significantly lower in pegmatitic granite and higher in granodiorite. This difference might be caused by the small amount of the sample in the XRD analysis and the uncertainty of roughly $5 \%$.

The porosity of veined gneiss, pegmatitic granite and granodiorite rocks have been studied by ${ }^{14} \mathrm{C}$ polymethylmetacrylate (C-14-PMMA) method (Hellmuth et al. 1994; Siitari-Kauppi, 2002) and the 
total porosity of the studied rocks has been found to vary between $0.5 \%$ and $0.7 \%$. It has been observed that all the main minerals in granodiorite are porous, (Kelokaski et al., 2006) whereas in pegmatitic granite, the porosity of the feldspars is low; close to the detection limit of the method $(0.05 \%)$ (Ikonen et al., 2015). There are also plenty of micro fractures in pegmatitic granite; both filled and open have been found to form a conductive network of migration pathways (Sammaljärvi et al., 2017). In veined gneiss, the porosity of biotite has been found to be slightly higher than that of feldspars. Quartz appears non-porous and the most porous phases are cordierite and the altered minerals like chlorite and muscovite that form clusters of highly porous phases (Kuva et al., 2016).

The specific surface areas of the crushed rocks and minerals were also studied (Table 4). The specific surface area of quartz and potassium feldspar was found to be very small compared to plagioclase and biotite and, furthermore, the specific surface area of biotite was found to be the largest. The differences in the specific surface areas are caused by the differences in the mineralogical structures. Veined gneiss is consisted of abundant biotite grains offering a lot of surface area whereas the granodiorite and pegmatitic granite mostly consist of quartz and feldspars with much less specific surface area.

In addition, the specific surface areas of small rock pieces $(2.5 \mathrm{~g})$ were also determined in the Chalmers University of Technology. The results were roughly one magnitude smaller than the results obtained for crushed rock. The results of the rock pieces were in good agreement with the results of the crushed rock so that the largest specific surface areas were obtained for veined gneiss, $0.6715 \pm 0.0464 \mathrm{~m}^{2} \mathrm{~g}^{-1}$. For pegmatitic granite, values of $0.0524 \pm 0.0007 \mathrm{~m}^{2} \mathrm{~g}^{-1}$ were determined and for Grimsel granodiorite, $0.0456 \pm 0.0003 \mathrm{~m}^{2} \mathrm{~g}^{-1}$. There was some dispersion in the results between the parallel samples due to the heterogeneity of the rocks, which affects the results in such a small scale.

Table 4. The specific surface areas of the studied rocks and minerals determined with the BET method in ascending order (Stellan Holgersson, Chalmers University of Technology). The grain size of the samples was $<0.3 \mathrm{~mm}$.

\section{BET specific surface area $\left(\mathrm{m}^{2} / \mathrm{g}\right)$}

Quartz 0.0604 \pm 0.0004

Potassium feldspar $0.0664 \pm 0.0002$

Plagioclase $\quad 0.1527 \pm 0.0002$

Granodiorite $\quad 0.3304 \pm 0.0022$

Pegmatitic granite $\quad 0.3416 \pm 0.0034$ 
Biotite $\quad 1.3948 \pm 0.0171$

Veined gneiss $\quad 1.4798 \pm 0.0155$

The cation exchange capacities of the rocks were determined with the ammonium acetate method (Muuri et al., 2016). The values obtained were $0.40 \mathrm{meq} / 100 \mathrm{~g}$ for granodiorite, $0.49 \mathrm{meq} / 100 \mathrm{~g}$ for pegmatitic granite and $1.32 \mathrm{meq} / 100 \mathrm{~g}$ for veined gneiss in $\mathrm{pH}$ 7. As a result, the portion of exchangeable cations for ion exchange is significantly higher in veined gneiss than in granodiorite and pegmatitic granite, which might be due to the high biotite content of veined gneiss.

\subsection{Adsorption sites}

Biotite, like its end member phlogopite, is composed of a sheet-like structure (Fig. 1) that consists of negatively and positively charged layers (Velde and Meunier, 2008): the negatively charged layers consist of tetrahedral $(\mathrm{T})$ and octahedral $(\mathrm{O})$ sheets that stack together to form 2:1 (TOT) layers with a characteristic repeat distance between two layers. These negatively charged layers are balanced by cations which are exchangeable to cations, such as barium, in the external solution (Fig. 2). Especially the cations located in the edge of the interlayer of the sheet structure are sensitive for cation exchange reactions (Fuller et al., 2014).

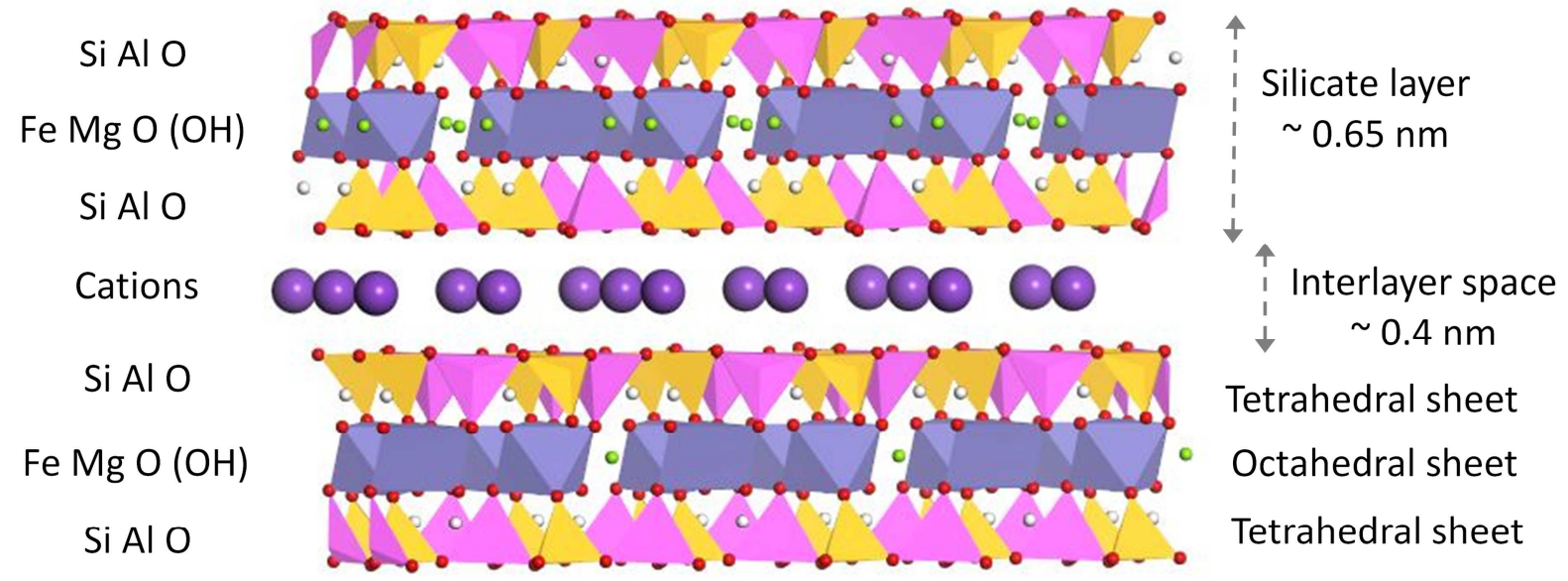

Fig 1. Biotite structure. Tetrahedral sheet: silicon - yellow and aluminium - aniline red. Octahedral sheet: iron - blue and magnesium - green. Interlayer: potassium - purple.

In Figure 2, the bonding geometry of the uppermost cations on the hydroxylated (110) surface of phlogopite is shown based on the molecular modeling using DFT methods. According to the results, 
the surface structure of the phlogopite does not depend on if the uppermost cation is potassium $\left(\mathrm{K}^{+}\right)$, cesium $\left(\mathrm{Cs}^{+}\right)$or barium $\left(\mathrm{Ba}^{2+}\right)$. In all the cases, the cations $\left(\mathrm{K}^{+}, \mathrm{Cs}^{+}\right.$and $\left.\mathrm{Ba}^{2+}\right)$ are bonded to four hydroxyl groups, so that the hydroxyl groups together with the cation (in the middle of the coordination sphere) form a planar quadrate coordination structure, the size of which is approximately $0.15 \mathrm{~nm}^{2}$. This structure binds the parallel TOT layers more strongly to each other so that the distance between the layers varies from $0.29 \mathrm{~nm}$ to $0.33 \mathrm{~nm}$. Because this distance is significantly shorter than the characteristic repeat distance between the layers in the bulk structure $(\sim 0.4 \mathrm{~nm})$, it is an indication that surface complexation reactions happen and that the uppermost interlayer cations have a strong effect on the surface properties of phlogopite. When the concentration of cations increases, the probability for surface complexation reactions is greater, the steric hindrance above the interlayer increases, and diffusion into the interlayer of phlogopite becomes more laborious, decreasing the portion of the Frayed Edge Site (FES) positions. This is consistent with the results of the PHREEQC modelling and the batch sorption experiments, the results of which are presented in the section 3.5. (Fig. 6). It was also concluded with the molecular modelling that the barium cations sorb on the same interlayer sites as cesium cations.

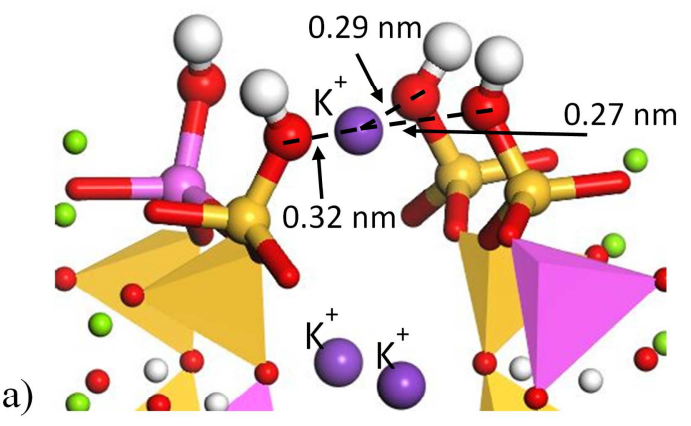

b)

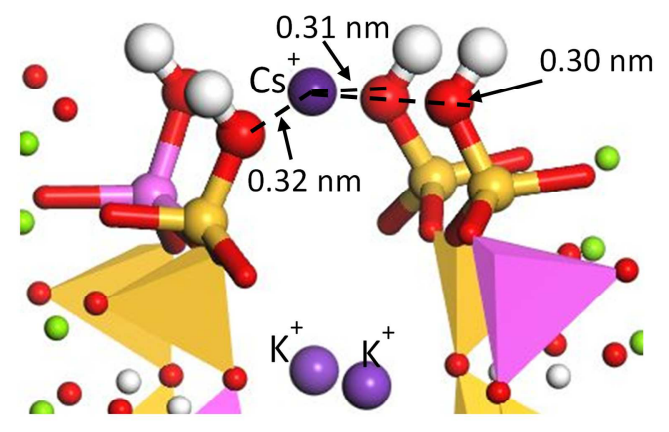

c)

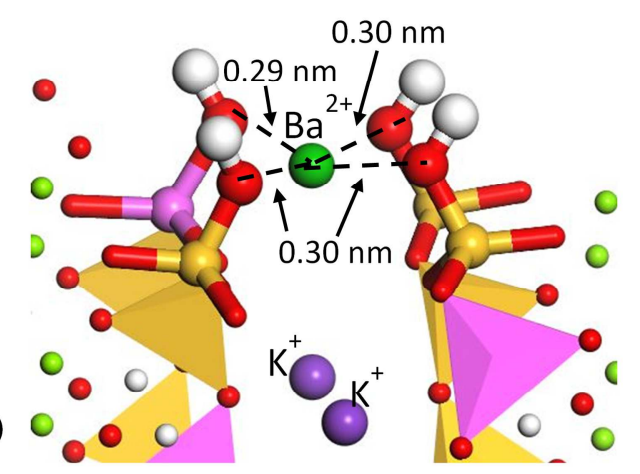

Fig 2. The hydroxylated (110) surface of phlogopite. a) Phlogopite with the interlayer distance 0.35 $\mathrm{nm}$ on the level of the uppermost cations, b) the uppermost $\mathrm{K}^{+}$ions replaced with $\mathrm{Cs}^{+}$ions: the interlayer distance $0.32-0.35 \mathrm{~nm}$, and c) the uppermost $\mathrm{K}^{+}$ions replaced with $\mathrm{Ba}^{2+}$ ions: the 

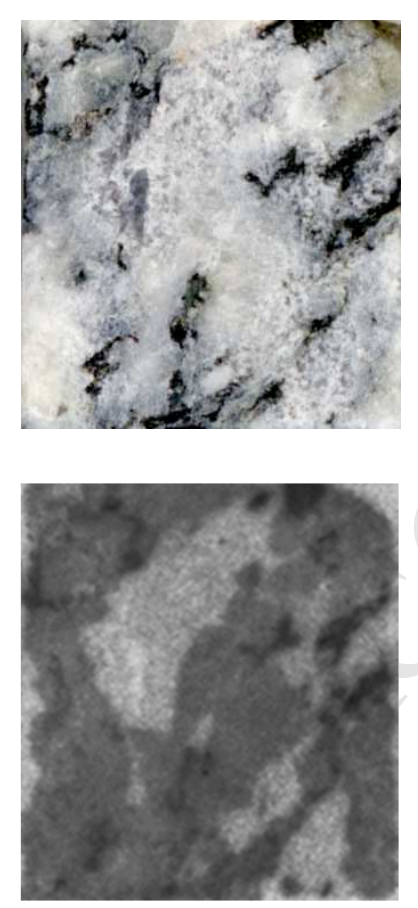
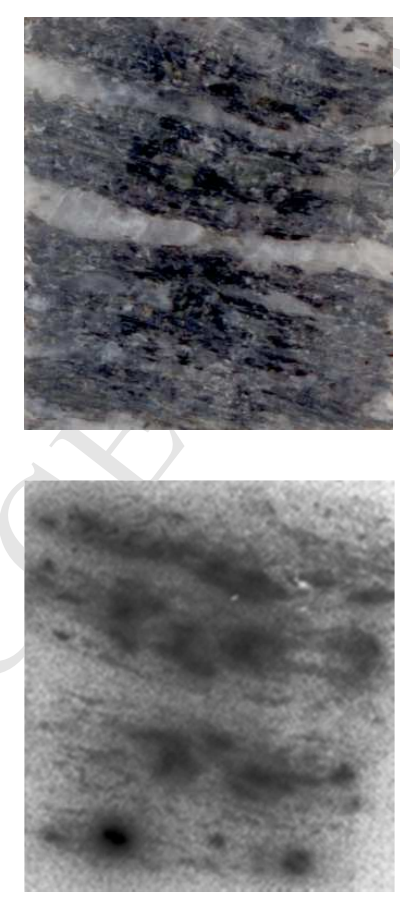

interlayer distance $0.29-0.33 \mathrm{~nm}$. Silicon: yellow. Aluminium: aniline red. Oxygen: red. Hydrogen: white. Magnesium: green.

\subsection{The spatial distribution of barium in the rock cubes}

The rock surfaces that had been in contact with the tracer solution for six months in the diffusion experiments were studied with autoradiography. It was discovered from the autoradiograms that the radioactive barium was sorbed most preferentially on the dark mica minerals of the rock (Fig. 3). This is most probably due to the sheet-like structure of the mica minerals, which offers plenty of specific surface area for the sorption to occur. This is seen clearly on the FE-SEM image of biotite taken from the intact surface of granodiorite (Fig. 4). As a contrast, the surface of, for example, quartz is mostly consisted of basal planes making the specific surface area of quartz significantly smaller than that of biotite. This leads to the negligible sorption of cations on quartz. In addition, the sorption of barium on plagioclase is most distinct in the granodiorite sample, where the plagioclase has been found to be more porous than in the veined gneiss and pegmatitic granite samples. The depth profiles of barium were studied qualitatively with autoradiography from the sliced samples. It was discovered that most of the barium activity was within the first millimetres from the surface of the rock. However, some activity was found throughout the samples.

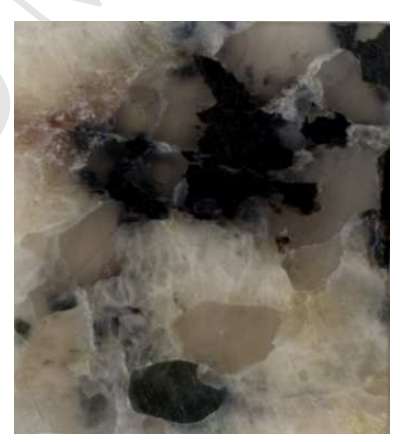

Fig 3. The digital images (upper) and the corresponding digital autoradiograms (lower) of a) granodiorite, b) veined gneiss and c) pegmatitic granite rock cubes. The width of the images is approximately $1 \mathrm{~cm}$. The darker areas on the autoradiograms correspond to higher barium activity. Different shades are associated with different minerals where the darkest shades are from mica 


\section{ACCEPTED MANUSCRIPT}

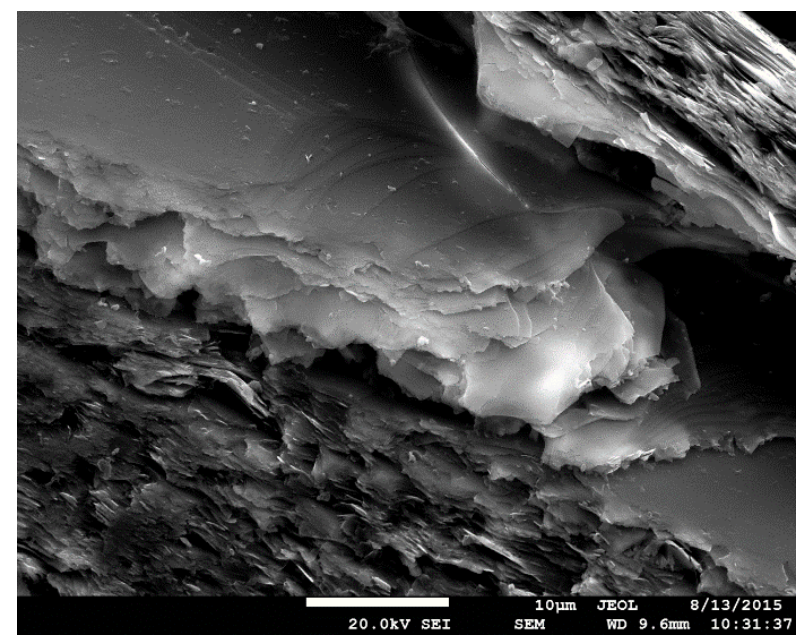

minerals, the medium shades are from feldspar and the lightest shade is from quartz. The dark spots with halo in the autoradiogram of veined gneiss is caused by natural uranium.

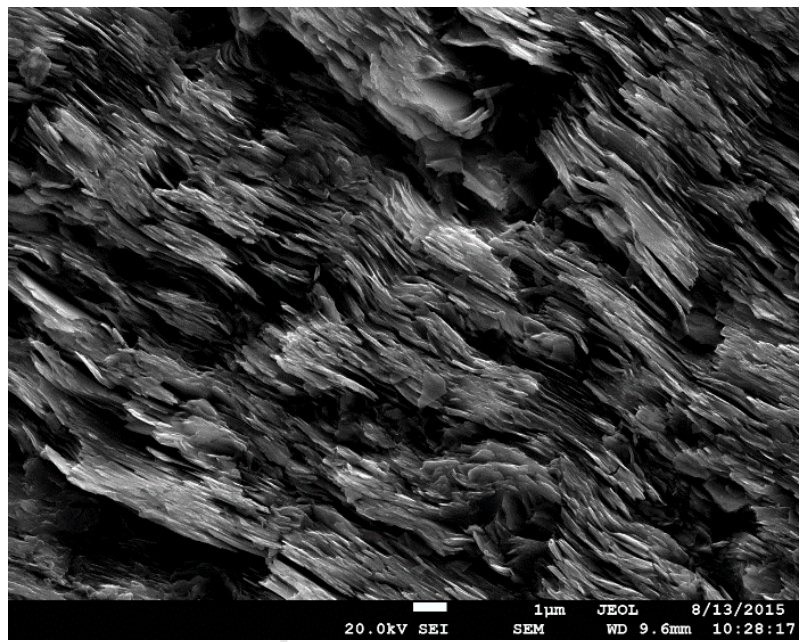

Fig 4. FE-SEM images of the structure of biotite in the veined gneiss cube. The roughness on the surface is due to the edges of the layered sheets, which corresponds to the large specific surface area.

\subsection{Elemental maps of the sawed surfaces of the rock cubes}

Firstly, samples that had not been in contact with the barium tracer solution were studied to confirm that none of the rock types investigated contained natural barium or the amounts were not detectable with the FE-SEM system. After this the same surfaces from the diffusion experiment that were studied with autoradiography were also studied. The sorbed barium on the rock cubes from the diffusion experiments was detectable with the FE-SEM system. The sorbed barium could mainly be detected in the biotite veins in the rock samples, most preferably in veins that were fissured. In addition, barium deposits followed fissures of the rock cubes and especially the locations of the magnesium and calcium bearing minerals in the rock (Fig. 5). This suggests that the barium was coprecipitated on calcium carbonate and detached via ion exchange on biotite and magnesium bearing minerals. In Fig 5 it can be seen that the barium deposits follow the geological feature of the calcite vein. 

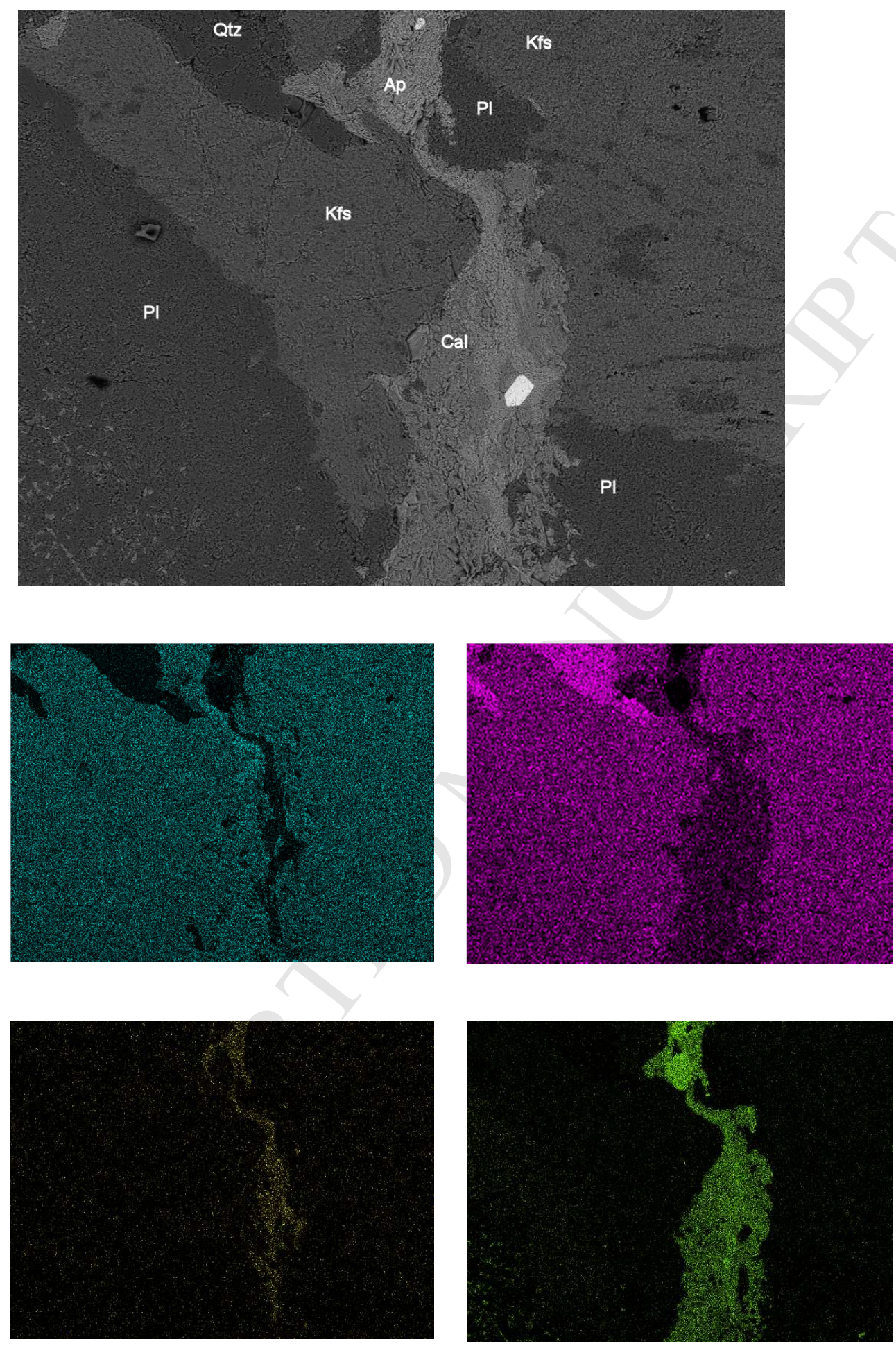

379 Fig 5. a) The backscattered electron image of a granodiorite site of the rock cube, where $380 \mathrm{Qtz}=$ quartz, Kfs=potassium feldspar, $\mathrm{Pl}=$ plagioclase, $\mathrm{Cal}=$ calcium carbonate and $\mathrm{Ap}=$ apatite. The 381 corresponding elemental maps of b) aluminium, c) silicon, d) barium and e) calcium. 
383 The sorption of barium on quartz was found to be very small in all studied concentrations and in 384 both studied groundwater simulants with distribution coefficient values of $1 \cdot 10^{-3} \mathrm{~m}^{3} / \mathrm{kg}$ in 385 magnitude (Fig. 6). The dispersion of the results was large, which may be due to resilient solid 386 phase in fine particles in the measured liquid phase. The interpretation of the results was difficult 387 due to the large uncertainties, but a slightly decreasing trend in the distribution coefficients as a 388 function of barium concentration could be seen. Furthermore, the distribution coefficient values in 389 Olkiluoto and Grimsel groundwater simulants were very similar within the uncertainty units of the 390 results. The small distribution coefficients obtained for quartz is most likely due to the small 391 specific surface area and ion exchange capacity of quartz. Additionally, it has been discovered in 392 previous studies that quartz is not a strong adsorbent for divalent cations and that, e.g. barium will migrate through silica-rich geological environments at essentially the same rate as the flowing

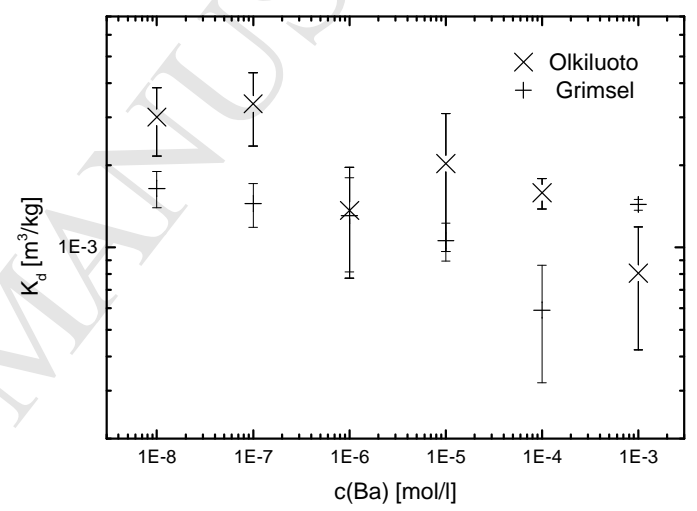

394 groundwater (Hayes et al., 2008).

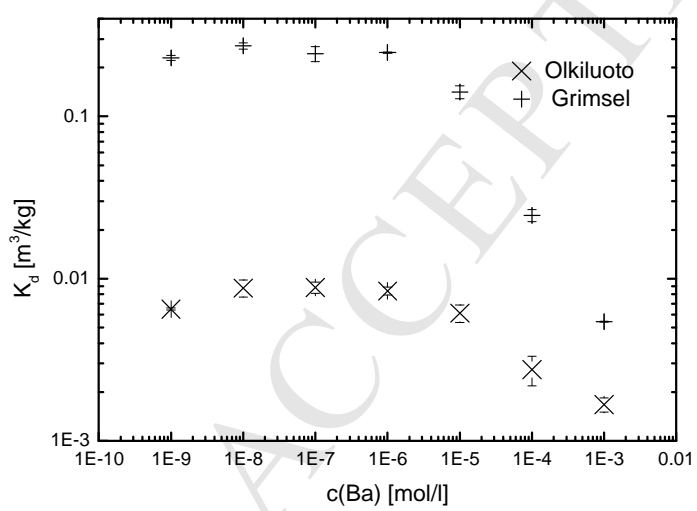

395 

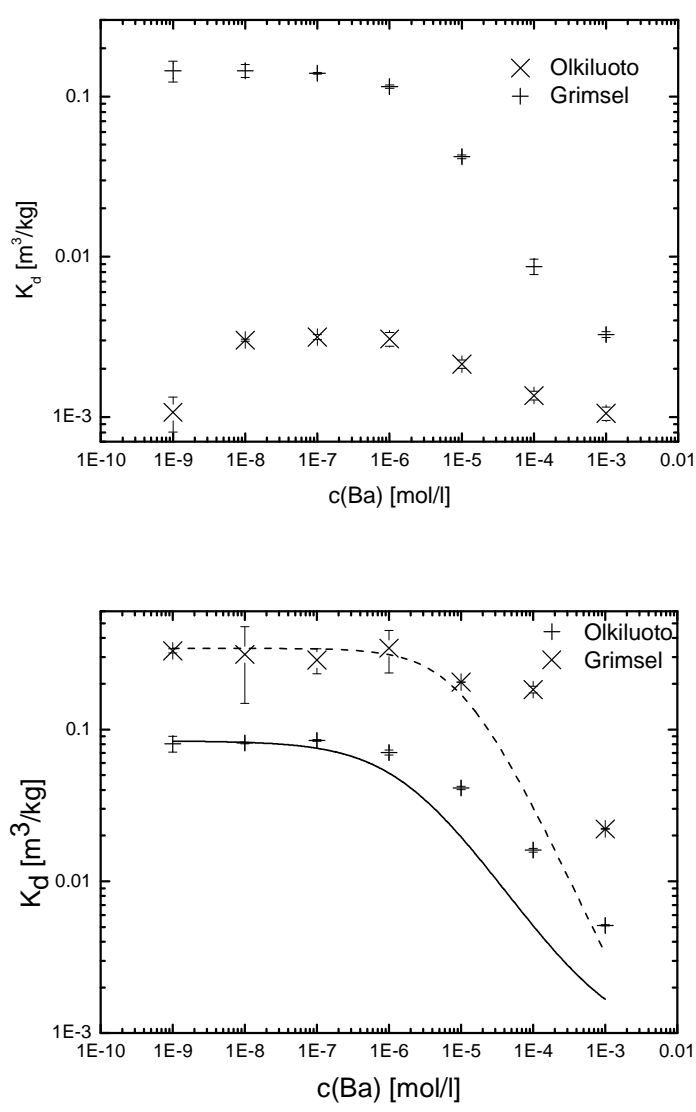

397

Fig 6. The distribution coefficients of barium as a function of barium concentration on a) quartz in the presence of Olkiluoto groundwater simulant at $\mathrm{pH} 6.5$ and Grimsel groundwater simulant at $\mathrm{pH}$ $8.0 \mathrm{~b})$ plagioclase in the presence of Olkiluoto groundwater simulant at $\mathrm{pH} 8.7$ and Grimsel groundwater simulant at $\mathrm{pH} 8.6 \mathrm{c}$ ) potassium feldspar in the presence of Olkiluoto groundwater simulant at $\mathrm{pH} 7.0$ and Grimsel groundwater simulant at $\mathrm{pH} 8.1$ and d) biotite in the presence of Olkiluoto groundwater simulant at $\mathrm{pH} 8.3$ and Grimsel groundwater simulant at $\mathrm{pH} 8.6$ where the curves represent the modelled data. All data points represent the average of triplicate samples and the uncertainties are given as the standard deviation of the mean.

The concentration of $\mathrm{SO}_{4}{ }^{2-}$ was $6.1 \cdot 10^{-5} \mathrm{M}$ in the Grimsel and $3.1 \cdot 10^{-6} \mathrm{M}$ in the Olkiluoto groundwater simulant. In theory, the solubility of $\mathrm{BaSO}_{4}$ should have exceeded at the highest $\mathrm{Ba}^{2+}$ concentrations in the groundwater simulant. However, $\mathrm{BaSO}_{4}$ was not allowed to precipitate in the calculations and it was not observed to do so in the experiments. In addition, if $\mathrm{BaSO}_{4}$ precipitation would have occurred in the highest $\mathrm{Ba}^{2+}$ concentrations, larger $\mathrm{K}_{\mathrm{d}}$ values would have been observed as the ${ }^{133} \mathrm{Ba}$ would have decreased in solution as $\mathrm{K}_{\mathrm{d}}$ is defined as the ratio of the concentration that has been removed from the solution by sorption (or precipitation) and concentration in solution. 
Larger $K_{d}$ values in the highest concentrations were not observed and, on the contrary, the $K_{d}$ values were smaller in the larger concentrations, which corresponds to the saturation of the sorption sites.

The distribution coefficients of barium on plagioclase showed a clear decreasing trend as the concentration of barium was increased. The decrease was not linear but instead the values were roughly constant at low concentrations and the decrease started at approximately $1 \cdot 10^{-6} \mathrm{~mol} / \mathrm{L}$ concentration. The sorption behaviour of barium on plagioclase was similar in both groundwater simulants although a difference in the magnitude of the results was observed (Fig. 6). The distribution coefficients were $0.009 \pm 0.001 \mathrm{~m}^{3} / \mathrm{kg}$ in $1 \cdot 10^{-7} \mathrm{~mol} / \mathrm{L}$ in the Olkiluoto groundwater simulant and $0.244 \pm 0.026 \mathrm{~m}^{3} / \mathrm{kg}$ in $1 \cdot 10^{-7} \mathrm{~mol} / \mathrm{L}$ in the Grimsel groundwater simulant. The difference is caused by the larger concentration of competing ions in the Olkiluoto groundwater simulant than in the Grimsel groundwater simulant. For example, the molality of $\mathrm{Ca}^{2+}$ ions was $1.3 \cdot 10^{-2} \mathrm{~mol} / \mathrm{kg}$ in the Olkiluoto groundwater simulant and $1.4 \cdot 10^{-4} \mathrm{~mol} / \mathrm{kg}$ in the Grimsel groundwater simulant with a difference of approximately two magnitudes. In addition, the ion radius and charge of $\mathrm{Ca}^{2+}(100 \mathrm{pm})$ is similar to $\mathrm{Ba}^{2+}(142 \mathrm{pm})$ (Shannon, 1976), which suggests that they may compete for the same sorption sites on the surface of the minerals.

The distribution coefficients of barium on potassium feldspar followed a very similar trend as on plagioclase (Fig. 6), although the distribution coefficients of barium were slightly smaller on potassium feldspar with values of $0.0032 \pm 0.0001 \mathrm{~m}^{3} / \mathrm{kg}$ in $1 \cdot 10^{-7} \mathrm{~mol} / \mathrm{L}$ in the Olkiluoto groundwater simulant and $0.140 \pm 0.001 \mathrm{~m}^{3} / \mathrm{kg}$ in $1 \cdot 10^{-7} \mathrm{~mol} / \mathrm{L}$ in the Grimsel groundwater simulant. In Olkiluoto groundwater simulant the distribution coefficient of barium on potassium feldspar was approximately one third of that on plagioclase and in Grimsel groundwater simulant approximately half of that on plagioclase. The slightly smaller distribution coefficients of barium on potassium feldspar than on plagioclase is most likely due to the smaller specific surface area of potassium feldspar $\left(0.0664 \pm 0.0002 \mathrm{~m}^{2} / \mathrm{g}\right)$ than of plagioclase $\left(0.1527 \pm 0.0002 \mathrm{~m}^{2} / \mathrm{g}\right)$. The higher specific surface area of plagioclase compared to that of potassium feldspar may be partly caused by the small impurities of dark minerals found in the XRD analyses.

The distribution coefficients of barium were largest on biotite with values of $0.084 \pm 0.001 \mathrm{~m}^{3} / \mathrm{kg}$ in $10^{-7} \mathrm{M}$ in the Olkiluoto groundwater simulant and $0.286 \pm 0.053 \mathrm{~m}^{3} / \mathrm{kg}$ in $10^{-7} \mathrm{M}$ in the Grimsel groundwater simulant. The large sorption on biotite can be explained with the sheeted structure of the mineral, where the edges of the layers offer a lot of surface area for the sorption to occur. Furthermore, it has been discovered in previous studies that the sorption of cesium is also most preferential on biotite of all the minerals investigated in this study (Muuri et al., 2016). A three site cation exchange model created by Bradbury and Baeyens (2000) has been used to explain the 
sorption behaviour of cesium on biotite (Kyllönen et al., 2014). In the three site model, in low concentrations the sorption is relatively high and constant as virtually all sorption occurs on the specific Frayed Edge Sites (FES) of the mineral, which possess a high affinity. As the concentration of the sorbing ion is increased, the sorption is decreased when the specific sites of the mineral become saturated and the sorption will occur on the non-specific and low affinity sites, Planar and Type II, sites (Bradbury and Baeyens, 2007).

According to our molecular modelling studies, cesium and barium are sorbed onto the same sites. Because in the earlier studies (Kyllönen et al., 2014), the sorption of cesium has been successfully described using a three site cation exchange model, it is presumable that the sorption of barium can also be modelled using the same model. It was discovered that the model (curve) described the sorption behaviour of barium on biotite fairly well (Fig. 6). However, it was discovered that the model underestimates the sorption of barium for high concentrations $\left(10^{-6} \mathrm{M}\right.$ to $\left.10^{-3} \mathrm{M}\right)$. The reason for this phenomenon needs to be further investigated. An attempt was made to model the data with a two-site cation exchange model as well, but the fit was not as successful as with the three site cation exchange model.

Batch sorption experiments were also conducted for the main rocks of the Olkiluoto and Grimsel sites. Firstly, veined gneiss from the Olkiluoto site was studied. The sorption behaviour of barium on veined gneiss followed the trend of the main minerals (Fig 7) and the distribution coefficients were $0.111 \pm 0.001 \mathrm{~m}^{3} / \mathrm{kg}$ in $10^{-7} \mathrm{M}$ in the Olkiluoto groundwater simulant. The veined gneiss used in this study was found to consist of quartz $(20 \%)$, plagioclase $(15 \%)$, potassium feldspar (10\%) and biotite $(35 \%)$ in the XRD analyses. The weighted distribution coefficient of barium on veined gneiss was calculated based on the mineral abundancies and their distribution coefficients and a result of $0.031 \mathrm{~m}^{3} / \mathrm{kg}$ in $10^{-7} \mathrm{M}$ was obtained. This value is much lower than the one obtained for veined gneiss in the batch sorption experiments, which is most probably caused by the effect of accessory clay minerals, which are not taken into account in the calculation (Sammaljärvi et al., 2017).

The main mineral of veined gneiss is biotite and, as a consequence, the three site sorption model obtained for biotite was applied to model the experimental sorption results. It can be seen from Figure 7 that the model fitted with the experimental data relatively well. The portion of the FES sites is below one percent in all investigated materials; veined gneiss, biotite in Olkiluoto groundwater simulant and biotite in Grimsel groundwater simulant (Table 5), which may be due to steric hindrance (Kodama and Komarneni, 1999). $\mathrm{Ba}^{2+}$ ions as divalent ions are fairly large ions 
478 whereas the interlayer sites are sterically hindered by the surrounding ions. The effect of this 479 phenomenon was studied with molecular modelling using DFT methods.

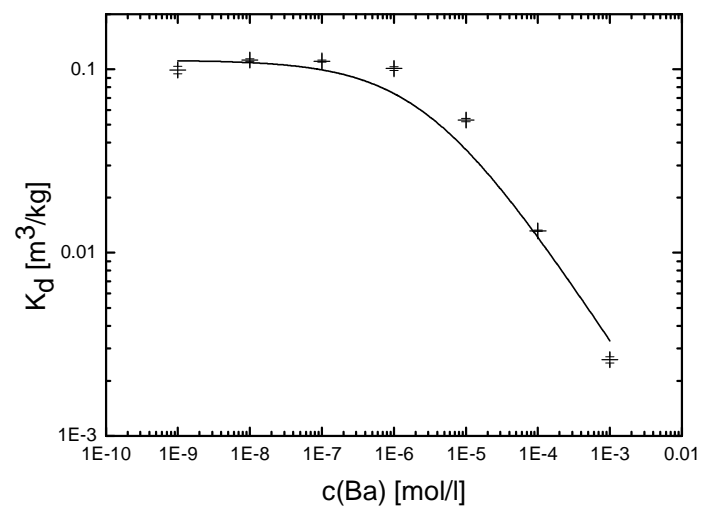

480

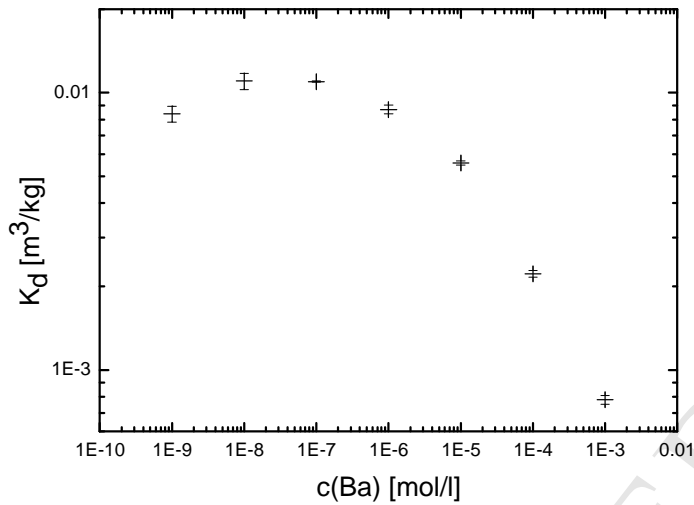

481

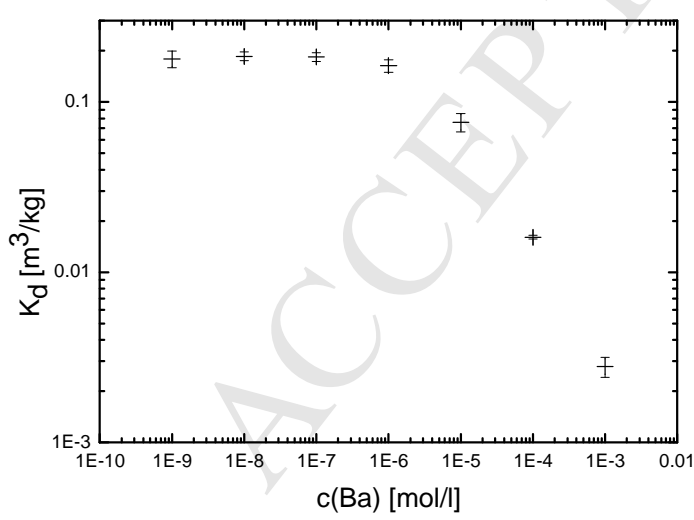

483 Fig 7. The distribution coefficients of barium as a function of barium concentration on a) veined 484 gneiss in the presence of Olkiluoto groundwater simulant at $\mathrm{pH} 7.8, \mathrm{~b}$ ) pegmatitic granite in the 485 presence of Olkiluoto groundwater simulant at $\mathrm{pH} 7.7$ and c) granodiorite in the presence of 486 Grimsel groundwater simulant at $\mathrm{pH}$ 8.6. All data points represent the average of triplicate samples 


\begin{tabular}{llll}
\hline & Veined gneiss & Biotite (Olkiluoto) & Biotite (Grimsel) \\
\hline Site Capacity & $96.78 \%$ & $96.78 \%$ & $99.14 \%$ \\
- Planar & $2.79 \%$ & $2.64 \%$ & $0.85 \%$ \\
- Type II & $0.43 \%$ & $0.58 \%$ & $0.01 \%$ \\
- FES & & & \\
\hline log $K_{c}(\mathrm{Ba})$ & 3.0 & 3.0 & 2.0 \\
- Planar & 3.0 & 3.0 & 3.5 \\
- Type II & 6.2 & 6.2 & 5.5 \\
- FES & & & \\
\hline
\end{tabular}

and the uncertainties are given as the standard deviation of the mean. The curve represents the modelled data.

Table 5. Computed selectivity coefficients $K_{c}$ and capacities for the three sites in the investigated materials acquired from the three site sorption model.

\section{$\begin{array}{lll}\text { Veined gneiss } & \text { Biotite (Olkiluoto) } & \text { Biotite (Grimsel) }\end{array}$}

492

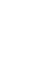


groundwater simulant. The calculated weighted distribution coefficient for barium on granodiorite was $0.140 \mathrm{~m}^{3} / \mathrm{kg}$ in $10^{-7} \mathrm{M}$, which was very close to the experimentally obtained value. The large distribution coefficients can be explained with the ionic strength of the Grimsel groundwater simulant, which is significantly smaller than that of the Olkiluoto groundwater simulant. As a consequence, there are less competing ions in the Grimsel groundwater simulant which can explain the large distribution coefficients of barium on granodiorite compared to pegmatitic granite, which is similar granitic rock containing only $5 \%$ of biotite and a high portion of quartz. In addition, the CEC values determined for granodiorite and pegmatitic granite were similar, which also suggests that the higher sorption on granodiorite might be due to the lower ionic strength of the groundwater simulant.

\section{Diffusion coefficients}

The tracer decrease of barium was found to be most remarkable in granodiorite whereas the tracer decrease in veined gneiss and pegmatitic granite was lower and roughly similar (Fig 8). This is most probably due to the differences in the ionic strengths as sorption on the sawed mineral surfaces is presumed to be the dominant process of the tracer decrease in the beginning of the experiment. Diffusion is a slow process and can be seen later on in the diffusion results. The diffusion modelling was done with Comsol Multiphysics to fit the experimental data acquired from the diffusion experiments. The fitting was done manually by using diffusion coefficient, distribution coefficient and porosity as fitting parameters. It was discovered in the fitting process that distribution coefficient had a dominating effect in the fitting, whereas the significance of diffusion coefficient and porosity was much smaller.

It was discovered from the model that the effective diffusion coefficient of barium was largest in granodiorite $\left(5 \cdot 10^{-12} \mathrm{~m}^{2} / \mathrm{s}\right)$ whereas the effective diffusion coefficients in veined gneiss and pegmatitic granite were clearly lower at $8 \cdot 10^{-14} \mathrm{~m}^{2} / \mathrm{s}$. The model produces a too small effective diffusion coefficient for pegmatitic granite, which suggests that the investigated materials cannot be treated as homogeneous but a heterogeneous diffusion model would be more suitable to describe the data. The larger effective diffusion coefficient in granodiorite might imply that the higher permeability of the rock allows the fast in-diffusion process.

Distribution coefficients were also used as fitting parameters in the model. The distribution coefficient of barium acquired from the model was $0.6 \cdot 10^{-3} \mathrm{~m}^{3} / \mathrm{kg}$ for granodiorite, $0.2 \cdot 10^{-3} \mathrm{~m}^{3} / \mathrm{kg}$ for veined gneiss and $0.4 \cdot 10^{-3} \mathrm{~m}^{3} / \mathrm{kg}$ for pegmatitic granite (Table 6). The distribution coefficients acquired from the model were approximately three orders of magnitude smaller than the values 
acquired from the batch experiments. However, the distribution coefficients were also calculated from the rock cube experiments for the rock cubes based on the total decrease of the barium tracer in solution during the six months' diffusion experiment and the results were $1.0 \cdot 10^{-2} \mathrm{~m}^{3} / \mathrm{kg}$ for granodiorite, $1.1 \cdot 10^{-3} \mathrm{~m}^{3} / \mathrm{kg}$ for veined gneiss and $3.5 \cdot 10^{-4} \mathrm{~m}^{3} / \mathrm{kg}$ for pegmatitic granite, which are clearly closer to the computed values. The great difference in the values of the batch and the cube experiments is due to specific surface area as the rock cubes offer much less specific surface area than the crushed rock.

Furthermore, the computed distribution coefficient of barium on pegmatitic granite was larger than the one of veined gneiss although in the batch sorption experiments the results were opposite. The model did not describe well enough the data of pegmatitic granite, which may be caused by the large heterogeneity in this scale due to the large grains in the rock. The model did not take into account the heterogeneity of the mineralogy and structure in the rock samples, which is evident in the distribution of barium measured in the autoradiograms. Finally, a significantly larger porosity (4 $\%$ ) compared to experimentally defined porosity (0.6\%) (Ikonen et al., 2015) was set for pegmatitic granite to fit the model to the experimental data. There is no correlation between the effective diffusion coefficient and porosity as there is a high variation in the spatial distribution of porosity and pore structure in these samples, which has been observed in previous studies as well (Kuva et al., 2016). The diffusion modelling conducted with Comsol Multiphysics was only a preliminary study and the model will be validated with TDRW modelling (Voutilainen et al., 2016) and with other possible tools that can take into account the mineralogical and structural heterogeneities of rocks in sorption and diffusion processes.

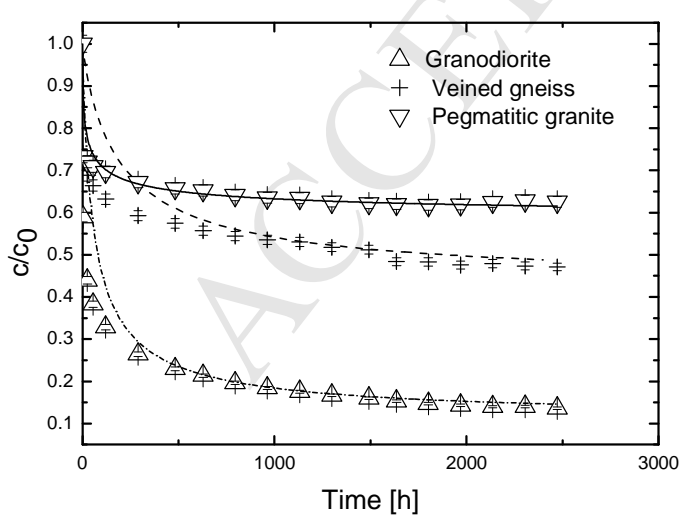

Fig 8. The relative tracer depletion of barium in solution and the diffusion model acquired by Comsol Multiphysics (curve) of granodiorite, veined gneiss and pegmatitic granite. Each of the data 
points represent an average of triplicate samples and the uncertainties are given as the standard deviation of the mean.

Table 6. The distribution coefficients, effective diffusion coefficients and porosities acquired from the Comsol Multiphysics diffusion model.

\section{Distribution coefficient $\left[\mathrm{m}^{3} / \mathrm{kg}\right] \quad$ Effective diffusion coefficient $\left[\mathrm{m}^{2} / \mathrm{s}\right]$ Porosity [\%]}

Granodiorite

Veined gneiss

Pegmatitic granite

$0.6 \cdot 10^{-3}$

$0.2 \cdot 10^{-3}$

$0.4 \cdot 10^{-3}$

$5 \cdot 10^{-12}$

0.65

$8 \cdot 10^{-14}$

$8 \cdot 10^{-14}$

\section{CONCLUSIONS}

The distribution coefficients of barium followed the trend of the specific surface areas. The distribution coefficients of barium from the batch sorption experiments were clearly largest on biotite and plagioclase, which have the largest specific surface areas of the minerals. The sorption of barium on quartz was found to be very small in all investigated concentrations in both groundwater simulants, which could be explained with the low ion exchange capacity and specific surface area of quartz. In addition, the distribution coefficients of barium on potassium feldspar were smaller than on plagioclase, which could be accounted by the smaller specific surface area of potassium feldspar. In addition, the effect of competing ions for sorption was evident with the two groundwater simulants with a salinity difference of approximately two magnitudes.

The sorption of barium on biotite was found to behave according to the three site model with PHREEQC for the sorption of trace metals on biotite and other mica minerals. At low barium concentrations $\left(<10^{-6} \mathrm{M}\right)$ barium was sorbed mainly on the selective FES of biotite and the sorption was high. After the saturation of FES, barium sorbs additionally on the Type II and Planar sites which leads to the reduced selectivity and reduced sorption at high concentrations $\left(>10^{-6} \mathrm{M}\right)$. The three site model acquired for biotite described the sorption behaviour of barium quite successfully. Molecular modelling performed to study the sorption mechanism of barium supports ion exchange as a sorption mechanism for barium on biotite.

The sorption behaviour of barium on crushed veined gneiss, pegmatitic granite and granodiorite followed the sorption behaviour on their main minerals. It was also discovered that the sorption was highest on granodiorite due to the low ionic strength of the Grimsel groundwater simulant used in 
the experiments, which provides less competing ions for the sorption than the Olkiluoto groundwater simulant. Of the rocks, the distribution coefficients were smallest in pegmatitic granite, which is mostly consisted of large grains of quartz and feldspars with significantly less specific surface area than biotite. Additionally, the feldspars in pegmatitic granite are less porous than those in granodiorite providing less specific surface area for sorption. The sorption of barium on veined gneiss was of the same magnitude as on granodiorite despite of the difference in the ionic strength of the groundwater simulant, which is mostly due to the large abundance of the highly sorbing mica minerals, for example biotite $(35 \%)$. It was confirmed in the autoradiograms and FESEM images that the sorption was most preferential on the biotite of the rock cubes. Additionally, the sorbed barium was also found in the fissures of the rocks which can be explained with the additional surface area released by the fracturing process. In addition, the CEC values determined for the rocks were largest in veined gneiss, which can also be due to the large biotite content.

The sorption results of the crushed rocks obtained from the laboratory experiments were systematically smaller than the sorption results obtained for the rock cubes, which is due to the increased specific surface area by the crushing of the rock. In addition, a clear effect of the ionic strength could be seen from the batch sorption experiments as the distribution coefficients were systematically a magnitude larger in the Grimsel groundwater simulant than in the saline Olkiluoto groundwater simulant. It could thus be concluded that the abundant cations in the Olkiluoto groundwater simulant compete extensively with the sorption of barium, which must be taken into consideration in the interpretation of the results from the in-situ experiments. Furthermore, the heterogeneity of the rock can be better taken into account in the safety calculations of the geological repository with the mineral specific distribution coefficients determined in this study. The intrusion depth of barium was not studied quantitatively in this study but it will be covered in future experiments that will be modelled as well.

The concentration decrease of barium in the diffusion experiments was found to be largest in granodiorite, which can be explained partly with the low salinity Grimsel groundwater simulant used in the experiments. In addition, Grimsel granodiorite has a large permeability, and, thus, a large conductivity, which may cause the large tracer decrease. The concentration decrease was smallest in pegmatitic granite although the effective diffusion coefficients of pegmatitic granite and veined gneiss were similar, which suggests that the model is not suitable to describe the results of pegmatitic granite. 


\section{ACKNOWLEDGEMENTS}

Stellan Holgersson is acknowledged for determining the specific surface areas of the rocks and minerals. We are very grateful for Marja Lehtonen for her help with FE-SEM and Antero Lindberg for obtaining the minerals used in the experiments. This work was supported by the Finnish Research Program on Nuclear Waste Management KYT2018.

\section{REFERENCES}

Aaltonen I., Engström J., Front K., Gehör S., Kosunen P., Kärki A., Mattila J., Paananen M. and Paulamäki S. (2016) Geology of Olkiluoto. POSIVA 2016-16. Posiva Oy.

Appelo C.A.J and Postma D. (2005) Geochemistry, groundwater and pollution. A.A. Balkema Publishers. Amsterdam.

Augustithis S.S. (1983) Leaching and diffusion in rocks and their weathering products. Theophrastus Publications S.A. Athens, Greece.

Boving T. and Grathwohl T. (2001) Tracer diffusion coefficients in sedimentary rocks: correlation to porosity and hydraulic conductivity. J. Contam. Hydrol. 53, 85-100.

Bradbury M.H. and Baeyens B. (2000) A generalized sorption model for the concentration dependent uptake of cesium by argillaceous rocks. J. Contam. Hydrol. 42, 141-163.

Clark S.J., Segall M.D., Pickard C.J., Hasnip P.J., Probert M.J., Refson K. and Payne M.C. (2005) First principles methods using CASTEP. Z. Kristallographie, 220, 567-570.

COMSOL Multiphysics. (2016) Introduction to COMSOL Multiphysics 5.2a, COMSOL Inc., MA, USA. Available: http://www.comsol.com.

Dassault Systèmes. (2014) Materials Studio, Release 8.0. San Diego: Dassault Systèmes BIOVIA Corp.

Fuller A.J., Shaw S., Peacock C.L., Trivedi D., Small J.S., Abrahamsen L.G. and Burke I.T. (2014) Ionic strenght and $\mathrm{pH}$ dependent multi-site sorption of Cs onto a micaceous aquifer sediment. Appl. Geochem. 40, 32-42.

Haavisto T. (2014) Synthesis of final disposal related nuclides. Working report 2014-15. Posiva Oy. Hakanen M., Ervanne H. and Puukko E. (2014) Safety Case for the Disposal of Spent Nuclear Fuel at Olkiluoto: Radionuclide Migration Parameters for the Geosphere. POSIVA 2012-41. Posiva Oy. 
648

649

650

651

652

653

654

655

656

657

658

659

660

661

662

663

664

665

666

667

668

669

670

671

672

673

674

675

676

Hayes P.L., Malin J.N., Konek C.T. and Geiger F.M. (2008) Interaction of Nitrate, Barium,

Strontium and Cadmium Ions with Fused Quartz/Water Interfaces Studied by Second Harmonic Generation. J. Phys. Chem. A 112, 660-668.

Hedström H. (2013) Radium sulphate and its co-precipitation behaviour with barium and strontium.

Doktorsavhandlingar vid Chalmers tekniska högskola. Ny serie nr 3484. Chalmers University of Technology.

Hellmuth K.H., Lukkarinen S. and Siitari-Kauppi M. (1994) Rock matrix studies with carbon-14polymethylmethacrylate (PMMA); method development and applications. Isotopenpraxis Environ. Health Stud. 30, 47-60.

Hellä P., Pitkänen P., Löfman J., Partamies S., Vuorinen U. and Wersin P. (2014) Safety Case for the Disposal of Spent Nuclear Fuel at Olkiluoto - Definition of Reference and Bounding Groundwaters, Buffer and Backfill Porewaters POSIVA 2014-04. Posiva Oy.

Hoehn E., Eikenberg J., Fierzb T., Drostc W. and Reichlmayrc E. (1998) The Grimsel Migration Experiment: field injection-withdrawal experiments in fractured rock with sorbing tracers. $J$. Contam. Hydrol. 34, 85-106.

Hu Q. and Möri A. (2008) Radionuclide transport in fractured granite interface zones. Phys. Chem. Earth PT A/B/C 33, 1042-1049.

Ikonen J., Sammaljärvi J., Siitari-Kauppi M., Voutilainen M., Lindberg A., Kuva J. and Timonen J. (2015) Investigation of rock matrix retention properties supporting laboratory studies I: Mineralogy, porosity and pore structure. Working report POSIVA 2014-68. Posiva Oy.

Ikonen J., Sardini P., Jokelainen L., Siitari-Kauppi M., Martin A. and Eikenberg J. (2016) The tritiated water and iodine migration in situ in Grimsel granodiorite. Part I: determination of the diffusion profile. J. Radioanal. Nucl. Chem. 310, 1041-1048.

Ikonen J., Sardini P., Siitari-Kauppi M. and Martin A. (2016) In situ migration of tritiated water and iodine in Grimsel granodiorite, part II: assessment of the diffusion coefficients by TDD modelling. J. Radioanal. Nucl. Chem. DOI 10.1007/s10967-016-5041-9

Jokelainen J., Meski T., Lindberg A., Soler J.M., Siitari-Kauppi M., Martin A. and Eikenberg J. (2013) The determination of ${ }^{134} \mathrm{Cs}$ and ${ }^{22} \mathrm{Na}$ diffusion profiles in granodiorite using gamma spectroscopy. J. Radioanal. Nucl. Chem. 295, 2153-2161. 
Kelokaski M., Siitari-Kauppi M., Sardini P., Möri A. and Hellmuth K.-H. (2006) Characterisation of pore space geometry by ${ }^{14} \mathrm{C}$-PMMA impregnation -development work for in situ studies. $J$. Geochem Explor. 90, 45-52.

Kodama T. and Komarneni S. (1999) Na-4-mica: $\mathrm{Cd}^{2+}, \mathrm{Ni}^{2+}, \mathrm{Co}^{2+}, \mathrm{Mn}^{2+}$ and $\mathrm{Zn}^{2+}$ ion exchange. $J$. Mater. Chem., 9, 533-539.

Kuva J., Voutilainen M., Kekäläinen P., Siitari-Kauppi M., Sammaljärvi J., Timonen J. and Koskinen L. (2016) Gas phase measurements of matrix diffusion in rock samples from Olkiluoto bedrock, Finland. Transport Porous Med. 115, 1-10.

Kyllönen J., Hakanen M., Lindberg A., Harjula R., Vehkamäki M. and Lehto J. (2014) Modeling of cesium sorption on biotite using cation exchange selectivity coefficients. Radiochim. Acta. 102, 919-929.

Kärki A. and Paulamäki S. Petrology of Olkiluoto. (2006) POSIVA 2006-02. Posiva Oy.

Leach A. R. (2001) Molecular Modelling, Principles and Applications, 2nd ed., Pearson Education Limited, Essex.

Lehto J. and Hou X. (2011) Chemistry and analysis of radionuclides: Laboratory techniques and methodology. Wiley-VCH. Weinham, Germany.

Miller B. and Marcos N. (2007) Process report -FEPs and scenarios for a spent fuel repository at Olkiluoto. POSIVA 2007-12. Posiva Oy.

Muuri E., Ikonen J., Matara-aho M., Lindberg A., Holgersson S., Voutilainen M., Siitari-Kauppi M. and Martin A. (2016) Behavior of Cs in Grimsel granodiorite: Sorption on main minerals and crushed rock. Radiochim. Acta 104, 575-582.

Möri A., Alexander W.R., Geckeis H., Hauser W., Schäfer T., Eikenberg J. and Fiertz T. (2003) The colloid and radionuclide retardation experiment at the Grimsel test site: influence of bentonite colloids on radionuclide migration in a fractured rock. Colloids Surf. A. 217; 33-47.

Möri A., Mazurek M., Adler M., Schild M., Siegesmund S., Vollbrecht A., Ota K., Ando T., Alexander W.R., Smith P.A., Haag P. and Bühler C. (2003) Grimsel Test Site Investigation Phase IV (1994-1996) The Nagra-JNC in-situ study of safety relevant radionuclide retardation in fractured crystalline rock. IV: The in-situ study of matrix porosity in the vicinity of a water conducting fracture. Technical report 00-08. Nagra, Wettingen. 
Mäder U.K., Fierz T., Frieg B., Eikenberg J., Rüthi M., Albinsson Y., Möri A., Ekberg S. and Stille P. (2006) Interaction of hyperalkaline fluid with fractured rock: Field and laboratory experiments of the HPF project (Grimsel test site, Switzerland). J. Geochem. Explor. 90, 68-94.

Parkhurst D.L. and Appelo C.A.J. (1999) User's guide to PHREEQC (version 2) - A computer program for speciation, batch-reaction, one-dimensional transport and inverse geochemical calculations. Water-Resources Investigations Report 99-4259. Denver, Colorado.

Pitkänen P., Snellman M. \& Vuorinen U. (1996) On the origin and chemical evolution of groundwater at the Olkiluoto site. POSIVA-96-04. Posiva Оy.

Posiva Oy. (2008) Olkiluoto Site Description 2008 Part 2. POSIVA 2009-01. Posiva Oy.

Posiva Oy. (2012) Safety Case for the Disposal of Spent Nuclear Fuel at Olkiluoto - Synthesis 2012. POSIVA 2012-12. Posiva Oy.

Posiva Oy. (2013) Safety Case for the Disposal of Spent Nuclear Fuel at Olkiluoto - Models and data for the repository system 2012. POSIVA 2013-01. Posiva Oy.

Sammaljärvi J., Lindberg A., Voutilainen M., Kuva J., Ikonen J., Johanson B., Siitari-Kauppi M., Pitkänen P. and Koskinen L. (2017) Multi-scale study of the mineral porosity of veined gneiss and pegmatitic granite from Olkiluoto, Western Finland. To be published.

Shannon R.D. (1976) Revised effective ionic radii and systematic studies of interatomic distances in halides and chalcogenides. Acta Cryst. A 32, 751-767.

Siitari-Kauppi M. (2002) Development of ${ }^{14}$ C-polymethylmethacrylate method for the characterisation of low porosity media: Application to rocks in geological barriers of nuclear waste storage. PhD thesis, University of Helsinki, Report Series in Radiochemistry 17.

Soler J.M., Landa J., Havlova V., Tachi Y., Ebina T., Sardini P., Siitari-Kauppi M., Eikenberg J. and Martin A.J. (2015) Comparative modeling of an in-situ diffusion experiment in granite at the Grimsel Test Site. J. Contam. Hydrol. 179, 89-101.

Svensk Kärnbränslehantering AB. (2006) Long-term Safety for KBS-3 Repositories at Forsmark and Laxemar - a first evaluation. SKB TR-06-09, Svensk Kärnbränslehantering AB.

Tachi Y., Ebina T., Takeda C., Saito T., Takahashi H., Ohuchi Y. and Martin A. (2015) Matrix diffusion and sorption of $\mathrm{Cs}^{+}, \mathrm{Na}^{+}, \mathrm{I}^{-}$and HTO in granodiorite: Laboratory-scale results and their extrapolation to the in-situ condition. J. Contam. Hydrol. 179, 10-24. 
735 Velde B. and Meunier A. (2008) The Origin of Clay Minerals in Soils and Weathered Rocks, 736 Springer-Verlag Berlin Heidelberg,

737 Voutilainen M., Poteri A., Helariutta K., Siitari-Kauppi M., Nilsson K., Andersson P., Byegård J., 738 Skålberg M., Kekäläinen P., Timonen J., Lindberg A., Pitkänen P., Kemppainen K., Liimatainen J., 739 Hautojärvi A. and Koskinen L. (2014) In-situ experiments for investigating the retention properties 740 of rock matrix in ONKALO, Olkiluoto, Finland-14258. In: Conference proceedings WM2014 741 Conference, Phoenix, AZ, 2-6 Mar 2014.

742 Voutilainen M., Siitari-Kauppi M., Sardini P., Kekäläinen P., Muuri E., Timonen J., and Martin A. 743 Modelling transport of cesium in Grimsel granodiorite with heterogenous structure and dynamic 744 update of $\mathrm{K}_{\mathrm{d}}$. Submitted to publication.

745 Widestrand H., Andersson P., Byegård J., Skarnemark G., Skålberg M. and Wass E. (2004) In-situ 746 Migration Experiments at Äspö Hard Rock Laboratory, Sweden: Results of Radioactive Tracer 747 Migration Studies in a Single Fracture. J. Radioanal. Nucl. Chem. 250, 501-517. 